\title{
Reverse Osmosis Membrane Chlorine Effects Reduction Using Kinetic Degradation Fluxion Media
}

\author{
Rawan Abu Eisheh, Jawad A. Shoqier
}

Earth and environmental sciences Department, Al-Quds University, Palestine

\begin{abstract}
Nowadays reverse osmosis is one of the most used technologies for water treatment and it is a favored method for potable water production from seawater. However, membrane fouling is a critical problem associated with reverse osmosis (RO) plants, since it has many negative impacts on RO efficiency, effectiveness and operation costs. Moreover, membrane cleaning techniques used to overcome fouling reduce the membrane life time, and sometimes it damage the membrane, also these techniques may create environmental issues related to the waste chemical disposal.

In this study the effectiveness of applying Kinetic Degradation Fluxion media (KDF) as pretreatment step for reducing fouling caused by high dosage of chlorine in $R O$ system was investigated. Each test was carried out using two membranes, reference or control membrane in which feed solution moved directly inside without passing through the KDF media (RO-only), and pretreatment membrane with feed solution passing through KDF media (RO-KDF). The comparison between the two systems in terms of salt rejection and permeate flow indicates that KDF-media effectiveness in cl2 removal is high and it can extend the lifetime of RO membrane 3 times at least.
\end{abstract}

Keywords- RO pretreatment, $\mathrm{KDF}$, Chlorine removal.

\section{INTRODUCTION}

Chlorination for RO pretreatment has been applied usually where biological fouling prevention is required. Chlorine is added continuously at the intake. A free residual chlorine concentration of $0.5-1.0 \mathrm{mg} / \mathrm{L}$ should be maintained through the whole pretreatment line. DE chlorination upstream of the membranes is required, however, to protect the membranes from oxidation. Membrane can withstand short-term exposure to free chlorine; however, its resistance is limited.

Patented KDF is a chemical compound consists of a highpurity alloy of both $\mathrm{Cu}$ and $\mathrm{Zn}$, generally $\mathrm{KDF}$ is used in a purification system as a profiler, before another, finer stage of filtration, like RO. In KDF media water passes through a bed of pure $\mathrm{KDF}$, as the water makes contact with the KDF particles the redox reaction takes place, removing such impurities as minerals, metals, dissolved oxygen and organic materials.

\section{MATERIALS AND METHODOLOGY}

TW30-1812-50 FILMTEC $^{\text {TM }}$ RO membrane for home drinking water was used for all experiments. This membrane can work under actually low pressure to reach high salt rejection rate up to at least $99 \%$, and permeate flows up to 50 gallons per day (gpd).Its chlorine tolerance is $0.1 \mathrm{ppm}$. CuZn filter for drinking water was used as KDFmedia. It consists of 11 patented reticulated discs with 2 inch diameter and 0.5 inch height for each disc. The discs are flexible, slightly oversized, lightweight, earth friendly, easy for installation and the porous nature.

Each test was conducted using two membranes, reference or control membrane in which feed water moved directly inside without passing through the KDF media, and pretreatment membrane with feed water passing through KDF media,Fig.1 shows a simplified schematic of the experiment design and layout.

Since the decline in salt rejection and flux rate results from fouling on the membrane, then this decline will be considered as the main RO performance parameter to determine the effect of KDF media on RO membrane fouling reduction thus the effectiveness of KDF media on fouling reduction can be roughly assessed by comparing the salt rejection and permeate flow rate in the absence and in the presence of KDF media. Accurate feed water analysis was conducted before designing the system; this analysis ensures that the potential of different types of fouling like bio fouling and metal fouling is very low.

\section{RO MEMBRANE PERFORMANCE PARAMETERS IN CHLORINE EXPERIMENTS}

The chlorine experiments was carried out in the period from $22 / 7 / 2015$ to $8 / 3 / 2016$, highly chlorinated solution with 
$5 \mathrm{mg} / \mathrm{l}$ concentration of chlorine was used for feeding the systems.

\subsection{Salt rejection}

a. $R O$-only salt rejection

$73.7 \%$ was the minimum recorded salt rejection for $\mathrm{RO}$ only system; logically it was obtained with the end of the experiment in the $41^{\text {th }}$ running hour as more chlorinated feed solution contacted with the membrane, in the initial hours of running the salt rejection reached $98.6 \%$ as a maximum value, salt rejection was slightly reduced during the first 16 running hours as membrane shows some resistance to short-term attack by chlorine as in fig. 2 then the salt rejection was continuously decreased due to the continuous oxidation by chlorine, $15 \%$ reduction in salt rejection is a fouling indicator therefore it was supposed that fouling was occurred in RO-only system within the $41^{\text {th }}$ running houras the salt rejection was $73.7 \%$ with $26.3 \%$ reduction.

\section{b. $R O-K D F$ salt rejection}

The RO-KDF system was running for the first 23 hours with the absolutely maximum value of the salt rejection which was between $98 \%$ and $98.8 \%$ as shown in fig.2, after 34 running hours a slight change in salt rejection occurred so it became $97.1 \%$ which is still considered as a very high salt rejection value. During the last 7 running hours the salt rejection was reduced to $95.8 \%$ which was the minimum measured value for salt rejection in RO-KDF system. For salt rejection any value greater than $90 \%$ can be considered as high therefore salt rejection level in RO-KDF system kept high after 41 running hours with $5 \mathrm{mg} / \mathrm{l}$ chlorine concentration.

The reduction rate of salt rejection was increased as chlorine removal by KDF media decreased thus the membrane attacked by more chlorine, as shown in fig. 4 the initial chlorine removal by KDF media was $100 \%$, then it began decreasing. From the $17^{\text {th }}$ running hour the chlorine concentration in the feed solution filtered by KDF media exceeded the allowable limit (1ppm), and it was increased as running hours increased resulting in higher reduction rate in salt rejection.

\subsection{Permeate flow}

RO permeate is a function of temperature, generally permeate flow increase as temperature increase, the experiments were carried out in range of temperature from $12.2^{\circ} \mathrm{C}$ to $28.7^{\circ} \mathrm{C}$. Typical permeate flow at $60 \mathrm{psig}$ is plotted to show the proper permeate flow at each temperature degree according to company recommendation. a. RO-only permeate flow

As shown in fig. 3 the minimum difference in permeate flow of RO and the typical permeate flow was 0 at the first running hour, while the maximum difference was $2 \mathrm{~L}$ in the 5 last running hours, with higher permeate flow produced by the RO-only system than the recommended one because the pores of the RO membrane were enlarged by the oxidative degradation of polyamide RO membranes leading to more permeate flow passed through the membrane. The difference is increased as more chlorinated feed solution was filtered by the RO membrane.

\section{b. RO-KDF permeate flow}

As shown in fig. 3 the difference in permeate flow of RO$\mathrm{KDF}$ and the typical permeate flow is less than $1 \mathrm{~L}$ for all the running period. The maximum difference was $0.8 \mathrm{~L}$ this value was measured 2 times in the 9th and 8th running hour. The difference was not regular so the permeate flow of RO$\mathrm{KDF}$ may be more or less than the recommended one.

\subsection{Chlorine removal by KDF}

$\mathrm{KDF}$ redox media is unique combination of copper and zinc that creates an electro-chemical reaction. During this reaction, electrons are transferred between molecules, and new elements are created. Some harmful contaminants are changed into harmless components. Free chlorine is changed into benign, water-soluble chloride, which is then carried harmlessly through the water supply. After chlorinated feed solution is filtered by KDF media $\mathrm{EC}$ is slightly increased due to the transformation of $\mathrm{Cl}_{2}$ to $\mathrm{Cl}^{-}$.

The chlorine removal by KDF media was $100 \%$ for the first 13 running hours then it decreased to $73 \%$ after 41 running hours, the RO-KDF membrane was exposed to $1.66 \mathrm{mg} / \mathrm{l}$ of $\mathrm{Cl}_{2}$ as a maximum dosage and this value is actually greater than the allowed chlorine tolerance for RO membrane, but the maximum concentration of chlorine in the final permeate flow was less than $0.8 \mathrm{mg} / \mathrm{l}$ and it is accepted according to World Health Organization (WHO) for drinking water. $\mathrm{Cl}_{2}$ concentration in the permeate flow in RO-only exceeded the limited value after 7 running hour only as in fig.4, the $\mathrm{Cl}_{2}$ rejection by $\mathrm{RO}$-only membrane almost stopped by the $25^{\text {th }}$ running hour so the concentration of $\mathrm{Cl}_{2}$ in the permeate flow was nearly equal to that in the feed solution.From the 11 discs of the KDF media only one was oxidized by chlorine during the 41 running hours with $1237 \mathrm{~L}$ of high chlorinated feed solution passed through it. 


\section{TABLES AND FIGURES}

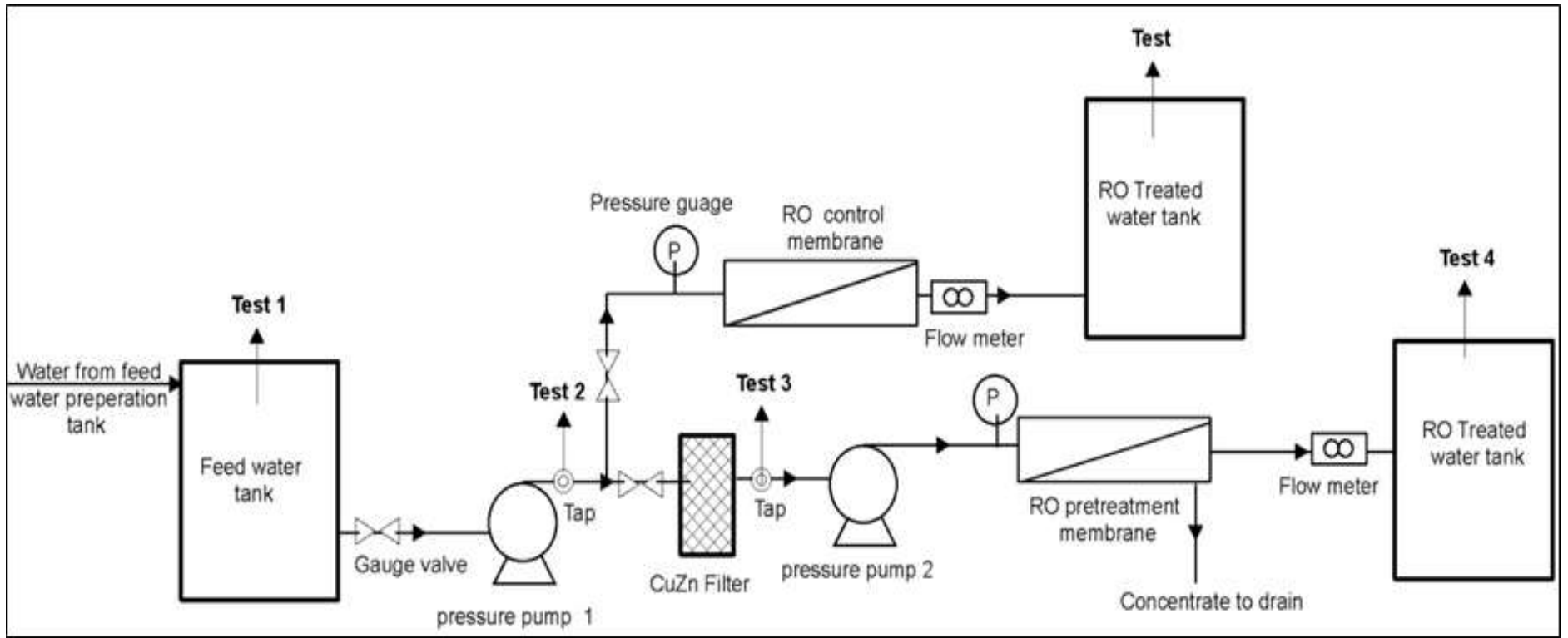

Fig. 1: Experiments schematic design for RO system.

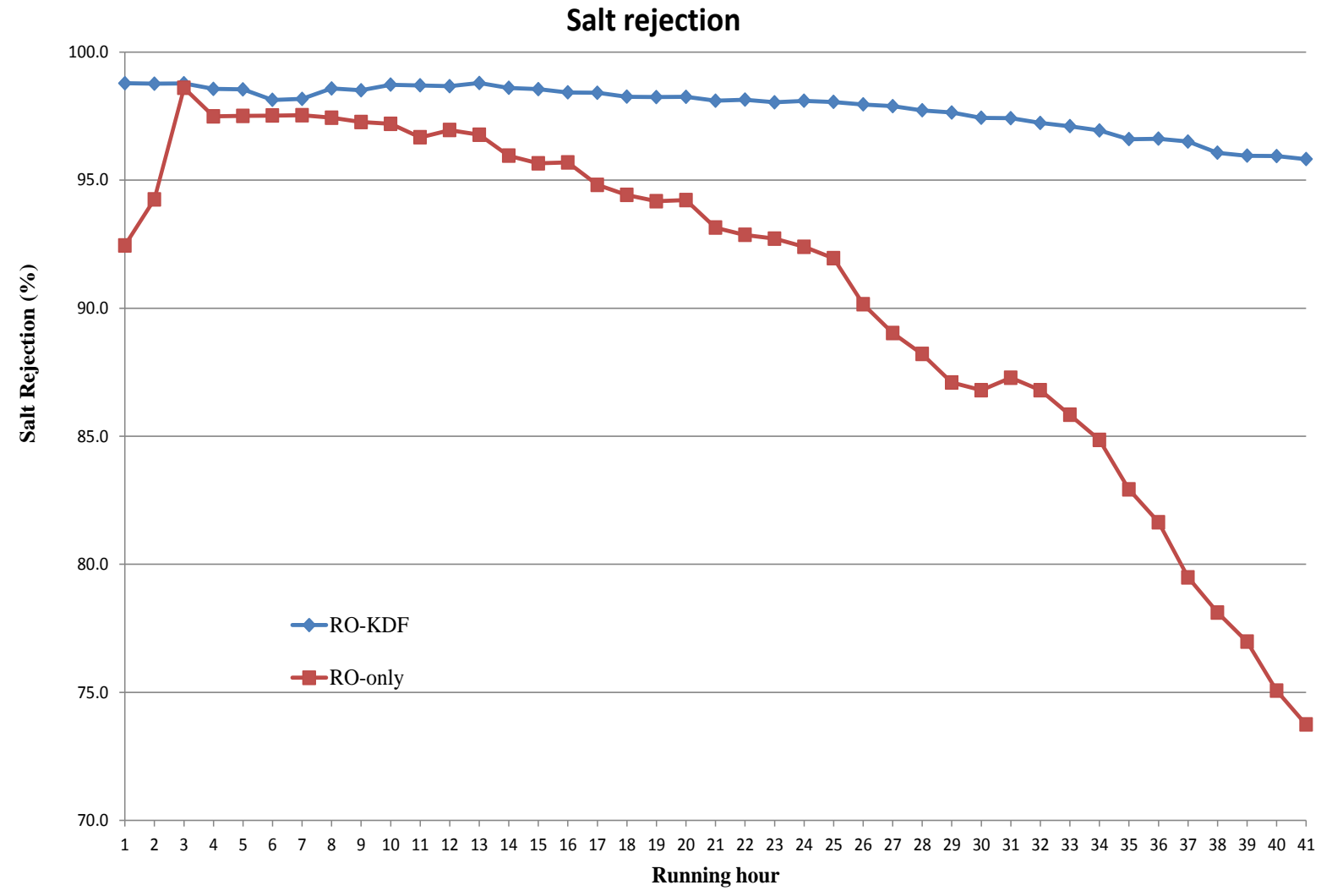

Fig.2: Salt rejection obtained by $R O$-only and $R O-K D F$ systems. 


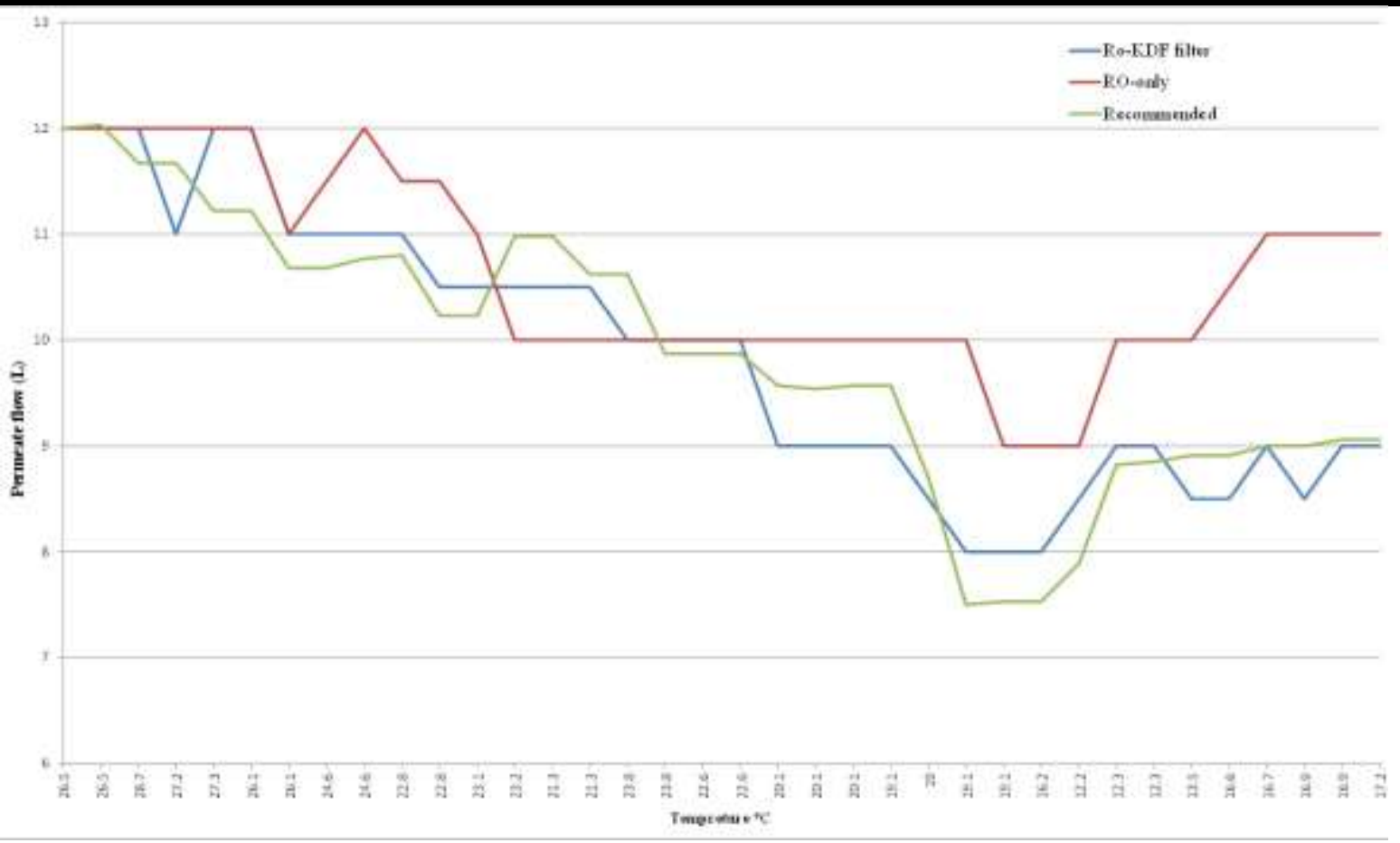

Fig. 3: Permeate flow produced by RO-only and RO-KDF systems.

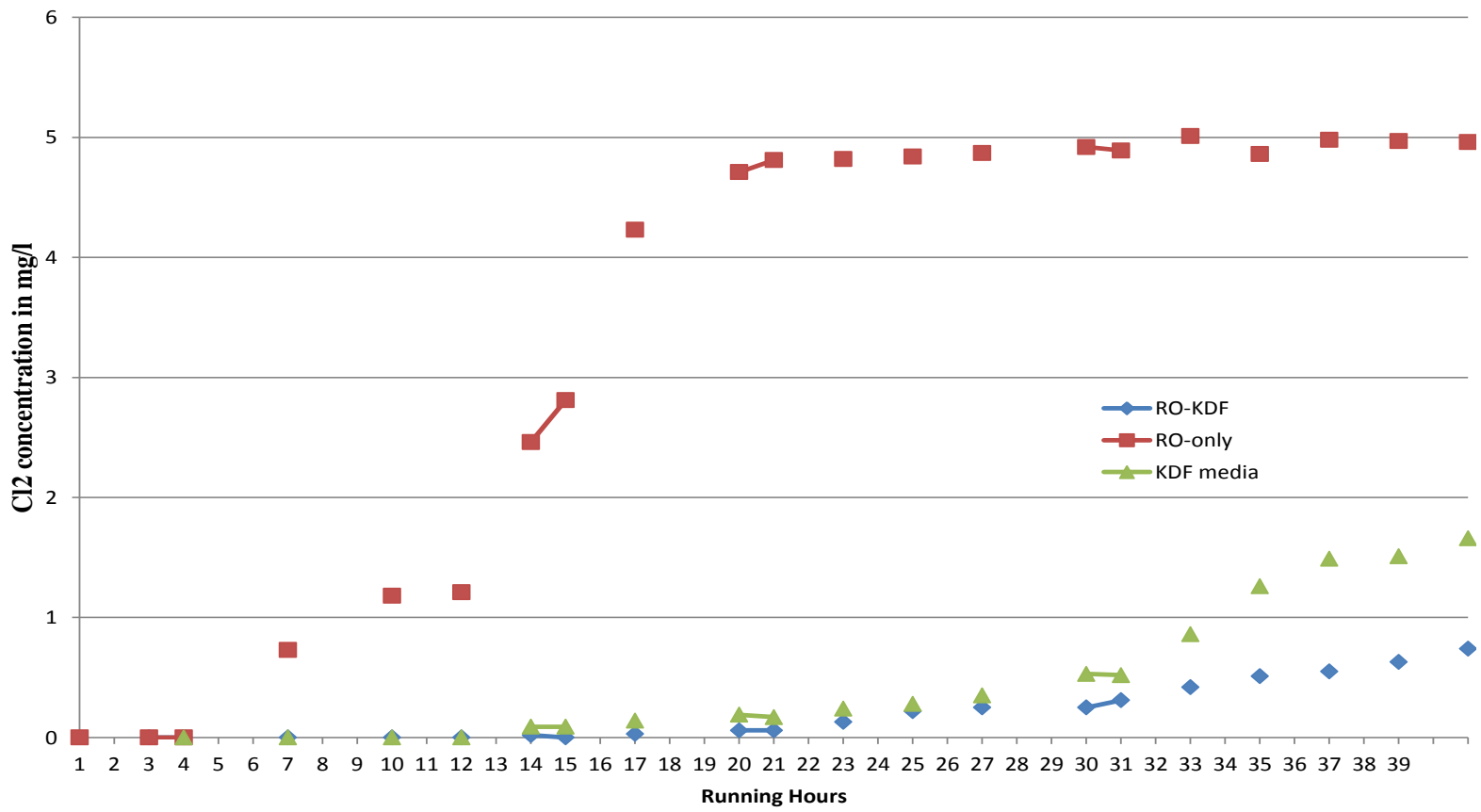

Fig. 4: $\mathrm{Cl}_{2}$ concentration in permeate flow in $\mathrm{RO}$-only and $\mathrm{RO}-\mathrm{KDF}$.

\section{CONCLUSIONS}

The efficiency and life of RO system depends on an effective pretreatment of the feed water. The pretreatment includes any process which can minimize fouling, scaling and membrane degradation to optimize product flow, salt rejection, product recovery and operating costs. When applying $\mathrm{KDF}$-media as pretreatment step for $\mathrm{Cl}_{2}$ removal both permeate flow and salt rejection in RO-KDF were improved so after 41 running hours the salt rejection was high and the permeate flow was adequate while fouling indicators raised early on RO-only system.Only one disc from KDF media was degraded in $\mathrm{Cl}_{2}$ experiments so it's expected that full media will extend the lifetime of the membrane 3times at least, thus KDF media can be 
considered as effective pretreatment step in RO system for chlorine removal and KDF media capability in $\mathrm{Cl}_{2}$ removal is very high.

\section{REFERENCES}

[1] Dow Water \& Process Solutions. FILMTEC ${ }^{\text {TM }}$ Reverse Osmosis Membranes Technical Manual, Form No. 609-00071- 0416.

[2] El-Dessouky H.\&Ettouney H.(2002). Fundamentals of salt water desalination. Elsevier.ISBN 0444508104 9780444508102.

[3] European Commission, Directorate-General for Research and Innovation (2010). Membrane Technologies for water applications. Publications Office of the European Union. Luxembourg. ISBN 978-92-79-17087-4.

[4] Express Customer Satisfaction Membranes (CSM). (2006). Technology manual for membranes. Saehan industries, Korea.

[5] KDF fluid treatment.(2003). KDF Process Media. (http://www.kdfft.com/pdfs/KDFProcessMedia.pdf)

[6] Mulder M.( 1996). Basic principles of membrane technology. Kluwer Academic Publishers. Netherlands. ISBN 978-94-009-1766-8.

[7] United States Environmental Protection Agency (USEPA). (2003). Membrane filtration guidance manual. DIANE Publishing, ISBN 1428900136, 9781428900134.

[8] White G.C. (1986). The Handbook of Chlorination. 2nd Edition. Van Nostrand Reinhold. New York. ISBN 978-0442292850.

[9] World Health Organization (WHO). (2013). Guidelines for drinking water quality, 4th Edition. Geneva. ISBN 9789241548151. 